\title{
Miguel Castro Caldas Irónica leveza e poesia discreta
}

\section{Sebastiana Fadda}

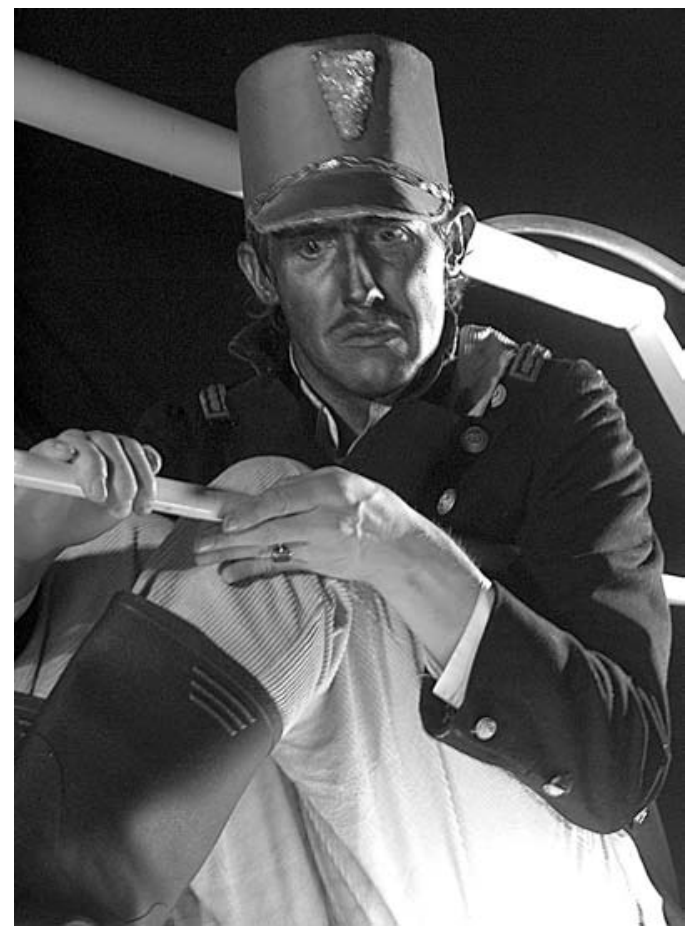

Escrevemos na "nota para a imprensa" que a atribuição de uma Menção Especial ao dramaturgo Miguel Castro Caldas se justificava pelo facto de vir revelando um singular labor de escrita que brinca ironicamente com as palavras num jogo subtil entre a desmistificação de lugares comuns e o encantamento poético. Dele se encenaram em 2005 Nunca-terra em vez de Peter Pan (co-produção Primeiros Sintomas e Culturgest), É bom boiar na banheira (coprodução Primeiros Sintomas e Chapitô) e a ele se deveu ainda a co-tradução de $A$ fábrica de nada, da holandesa Judith Herzberg, que os Artistas Unidos levaram à cena também em 2005 numa co-produção com a Culturgest.

Por ocasião dos encontros para o projecto

Descobridores do teatro português... 2004, organizado pelo Atelier Européen de la Traduction de Orléans em parceria com os Artistas Unidos e que decorreu no Teatro Taborda há dois anos, Miguel Castro Caldas falou de si próprio como de um "aprendiz da escrita". Referia-se aos dois livros de narrativa publicados até então, ou seja Queres crescer e depois não cabes na banheira e As sete ilhas de Lisboa. Quanto à bibliografia teatral, na altura constava de dois títulos: A montanha também quem e 0 homem do pé direito, ambas de 2003, a primeira ainda hoje inédita e a segunda editada com 0 homem da picareta, de 2004.

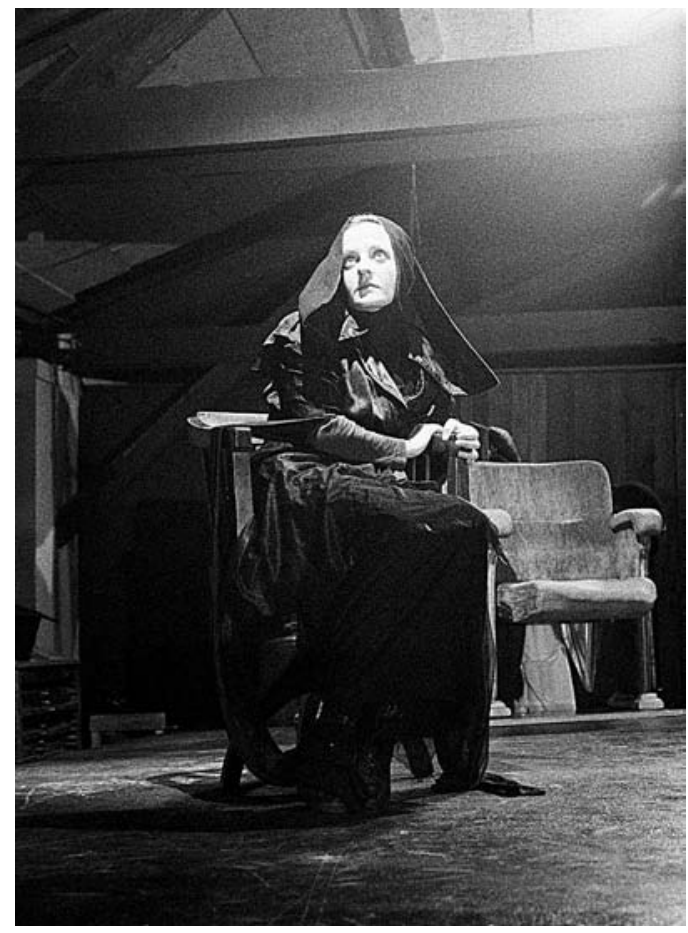

Ébom boiar na banheira de Miguel Castro Caldas, enc. Bruno Bravo, Primeiros Sintomas / Chapitô, 2005 (Tiago Viegas), fot. Chapitô.

Conto de Natal de Miguel Castro Caldas, enc. Bruno Bravo, Primeiros Sintomas, 2004 (Sandra Faleiro), fot. João Lopes.

Em relação à dramaturgia, ainda no evento lembrado, o jovem autor autodefinia-se como um caso especial, pois a sua ligação com o palco devia-se a uma colaboração intensa e exclusiva com Bruno Bravo e o grupo Primeiros Sintomas. Acrescentou, ainda, sentir-se intimidado pelos mitos e símbolos que normalmente atraem os outros escritores (esclarecendo recentemente que isso é verdade na medida em que os mitos e os símbolos são tidos como absolutos). Mas assumiu, isso sim e sem reservas, a fascinação por uma série reduzida de elementos e de recursos estilísticos que vão do gosto pelo surrealismo e pela paródia à pequena filosofia do quotidiano, autosituando-se mais em geral no âmbito da filosofia e do paradoxo.

E é um quotidiano não isento de rasgos grotescos que caracteriza as peças 0 homem do pé direito' e 0 homem da picareta'. Os dois textos não excluem um sentido poético peculiar, derivado mais das situações evocadas pelas palavras do que do seu potencial ritmico e sonoro. Nem faltam referências culturais de origem culta, popular ou fantástica: as citações do Romanceiro popular português por exemplo, mas também as alusões à fábula de Hansel e Gretel, para se censurar a miséria geradora do cinismo e da entrega das crianças a si próprias; ou a convocação de Fialho de Almeida e Pinheiro Chagas, bem como dos homens comuns,
$>$

Estreada em Outubro de 2003 na Associação

Cultural Abril em Maio.

2 Estreada em Setembro de 2004 no Espaço Karnart. 


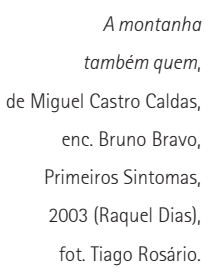

Conto de Natal, de Miguel Castro Caldas,

enc. Bruno Bravo, Primeiros Sintomas, 2004 (Raquel Dias,

Filomena Oliveira, Sandra Faleiro e Peter Michael), fot. João Lopes.

Conto de Natal, de Miguel Castro Caldas,

enc. Bruno Bravo, Primeiros Sintomas, 2004

(Filomena Oliveira,

Sandra Faleiro e Ana Brandão),

fot. João Lopes.

Estreada em Novembro de 2005 com encenação de Jorge Silva Melo, numa co-produção Culturgest /

Artistas Unidos e em principio destinada - mas não em exclusivo -a um público infanto-juvenil.

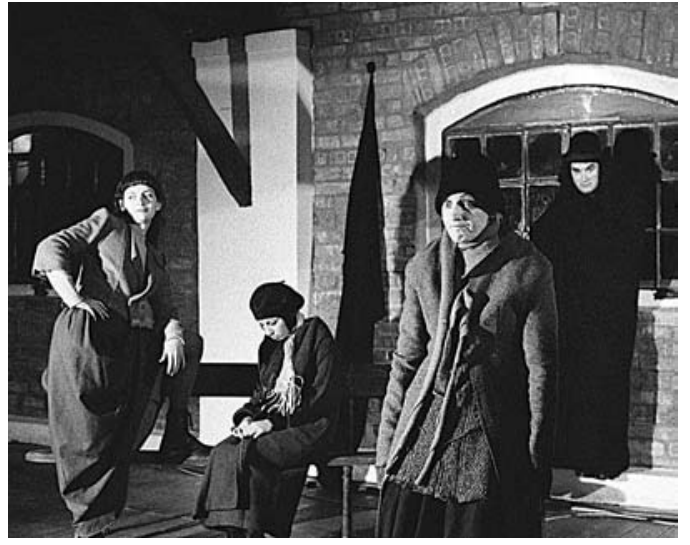

para se criticar a degradação do património imobiliário português. Essas duas peças configuram-se, ainda, como textos interpelativos, onde um espaço importante, mesmo que diluído no registo lúdico dos jogos de palavras, das metáteses ou do grotesco, é ocupado pelas constantes interrogações, sejam elas sobre a identidade, escorregadia e incerta, ou sobre o valor da escrita e da linguagem, duvidoso quanto baste.

Nessa linha do paradoxo poético e do desassosego temático inscrevem-se também as peças levadas à cena respectivamente em Setembro e Dezembro de 2005: Nuncaterra em vez de Peter Pan, e baseada numa possivel continuação da aventura de Peter Pan, e É bom boiar na banheira, mais abertamente destinada a um público infantil, ambas encenadas por Bruno Bravo. Foi-se assim cimentando aquela relação artística e pessoal que determinou o ingresso e vem suscitando a permanência de Miguel Castro Caldas na escrita dramática, permitindo-Ihe desenvolver um discurso singular e uma significativa experiência directa com a cena, não desdenhando a prática da intertextualidade entre produção narrativa e dramatúrgica.

Importa, também, não esquecer mais uma frutífera colaboração do autor em 2005, com os Artistas Unidos desta vez, e em veste de adaptador da tradução de David
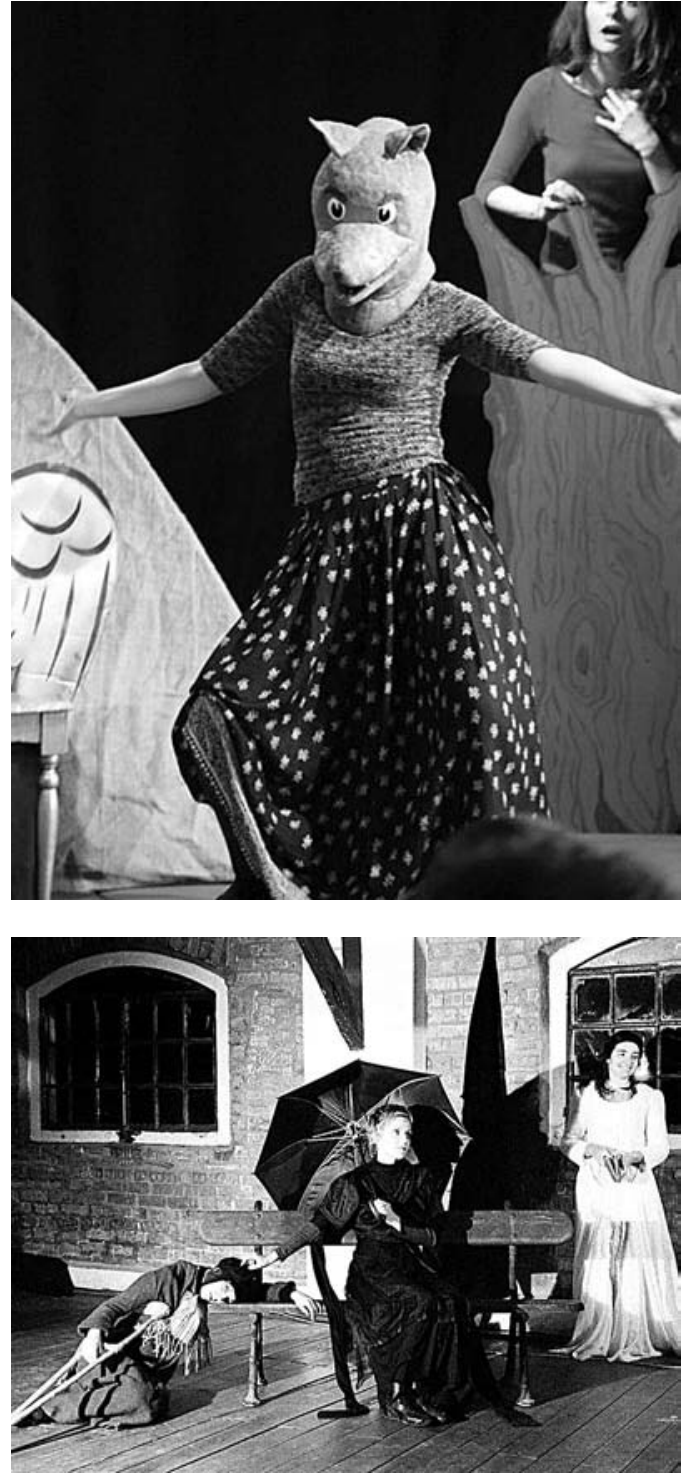

Bracke da peça musical A fábrica de nada, de Judith Herzberg ${ }^{3}$.

Nunca-terra em vez de Peter Pan é um texto divertido, bem disposto e faz dos trocadilhos, dos jogos de palavras, das assonâncias e do valor musical da palavra um dos seus pontos de força. Quanto ao tema, gira em torno das dificuldades ligadas ao crescimento do corpo, ao abandono da infância e à entrada na idade adulta. Na cena os actores tiveram desempenhos muito equilibrados. A parte musical tinha grande relevo e por vezes surgia em consonância com uma linguagem em que abundava um nonsense pertinente, não gratuito e que, antes pelo contrário, acrescentava coerência ao tom geral da peça. A cenografia, os figurinos e os adereços foram escolhidos com cuidado e eram muito coloridos, sugerindo um universo a meio caminho entre a banda desenhada e a ilustração de livros para infância.

É bom boiar na banheira reitera certos tropismos típicos do universo do autor: trocadilhos, jogos de palavras, assonâncias e musicalidade da palavra. 0 assunto principal configura-se como uma glosa do tema tratado no espectáculo anterior, ou seja, a dificuldade de crescer. Quanto às personagens que deram vida à acção cénica, vinham do imaginário infantil mais tradicional: uma bailarina, um soldadinho de chumbo e uma boneca de trapos. E foi no sentido assumidamente mais tradicional que os actores 


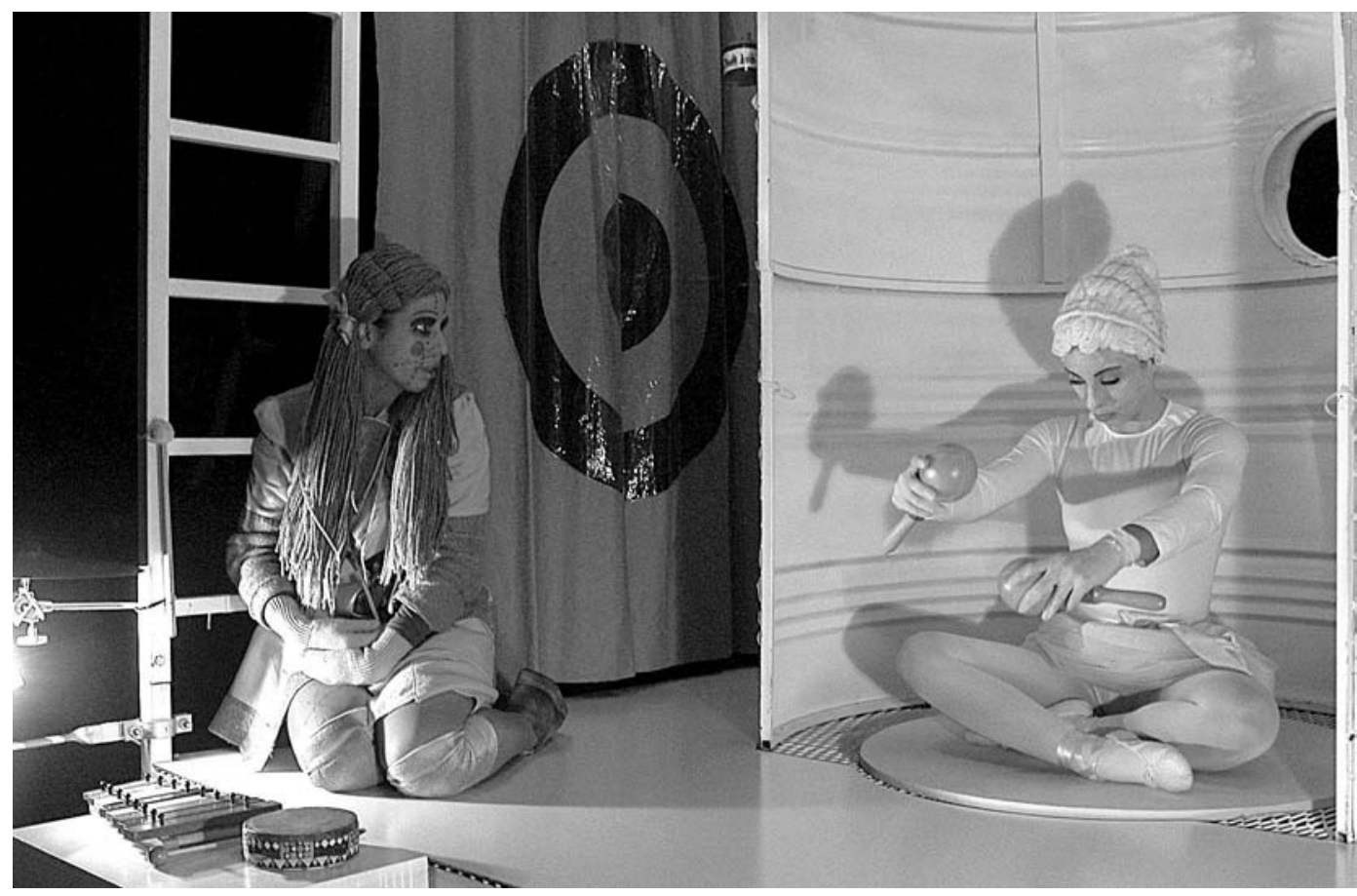

Ébom boiar na banheira de Miguel Castro Caldas, enc. Bruno Bravo, Primeiros Sintomas / Chapitô, 2005 (Gina Tocchetto e Nádia Santos), fot. Chapitô.

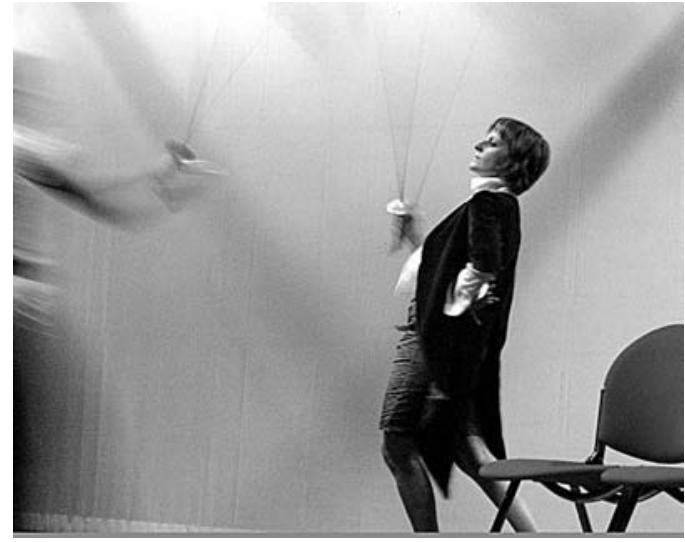

desempenharam os seus papéis, tendo movimentos quase mecânicos a bailarina (ligada aos sons dos carilhões) e o soldadinho de chumbo (ligado às marchas militares), mais soltos a boneca de trapos (sendo mole e feita de materiais de recuperação), num dispositivo cénico que lembrava vagamente as caixas de lata onde antigamente se guardavam os brinquedos.

Em A fábrica de nada o enredo tem implicações simbólicas que transcendem a sua aparente simplicidade: depois do fecho de uma fábrica de cinzeiros, os operários decidem tomar conta da situação e manter a fábrica aberta para produzir "nada". Há uma crítica inequívoca aos mecanismos que regem uma sociedade de um liberalismo selvagem, cujas forças motoras assentam no dinheiro, na produção e no consumo. A sugestão burlesca da autora é um alerta, o desfecho uma solução humana de reivindicação do direito a existir mesmo sem pertencer aos mecanismos produtivos. Actores e músicos partilharam o palco dando vida a soluções inovadoras, coreografando as partituras que percorriam um vasto repertório, do samba ao flamenco, passando por apontamentos rock e fraseggi de natureza operática. Neste caso, importa sublinhar que, por trás da voz da autora, são perceptiveis as afinidades e cumplicidades dos mediadores do texto para português.

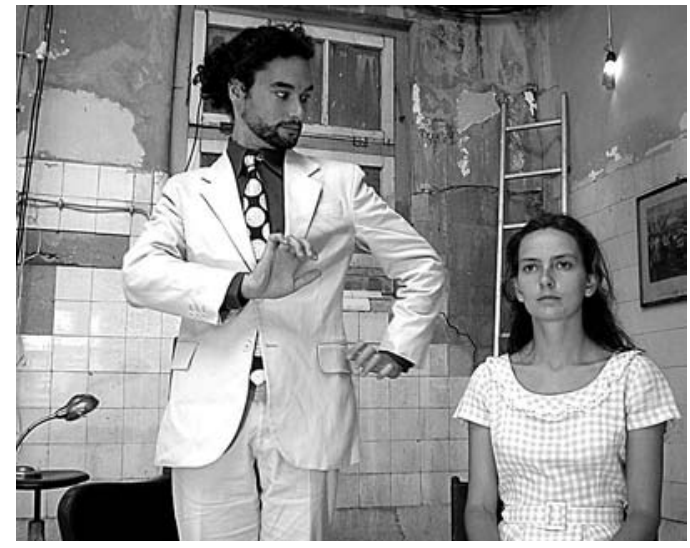

A voz de Miguel Castro Caldas tem um timbre muito pessoal. 0 autor sabe integrar-se com humildade nos colectivos teatrais, adaptando-se às exigências da cena e dos encenadores, contribuindo para a criação de espectáculos que fazem apelo à vivacidade, à sensibilidade e à inteligência, abrindo o palco a uma ternura consoladora, a um sentimento poético discreto, a um sentido de humor subtil e a uma leveza irónica no tratamento de temas ligados à existência. Detecta-se, aliás, aquela leveza por vezes em estado de graça de que falava Italo Calvino numa das suas Lições americanas, também conhecidas como Seis propostas para o novo milénio. Ou seja, uma leveza irónica que bem se integra num teatro do paradoxo.

\section{Referências bibliográficas}

CALDAS, Miguel Castro (2002), Queres crescer e depois não cabes na banheira, Porto, Âmbar. - - (2004), As sete ilhas de Lisboa, Porto, Âmbar.

- - (2005), O homem do pé direito e O homem da picareta, Lisboa, Cotovia \&t Artistas Unidos, Livrinhos de teatro.

- - (2005), Nunca-terra em vez de Peter Pan, Lisboa, Primeiros sintomas.

CALVINO, İtalo (1993), Seis propostas para o novo milénio: lições americanas (1985), trad. José Colaço Barreiros, Lisboa, Teorema.
Nunca-terra em vez de Peter Pan, de Miguel Castro Caldas, enc. Bruno Bravo, Primeiros Sintomas / Culturgest (Sandra Faleiro), fot. Folha.

Ohomem da picareta

de Miguel Castro Caldas, enc. Bruno Bravo, Primeiros Sintomas, 2004 (Peter Michael e Raquel Dias), fot. Bruno Bravo. 